\title{
Pirates as an Ideal
}

Umme Abida, Paul Hitchens, Bibi Laegaard \& Sheldon Rozario

At least 12 foreign ships are being held hostage in the waters off Eyl in the Nugal region, 300 nautical miles south of Africa's Horn, including a Ukrainian vessel, the MV Faina, loaded with 33 tanks and ammunition that was hijacked in September.

The captured ships are being closely watched by hundreds of pirates aboard boats equipped with satellite phones and GPS devices. Hundreds more gunmen provide back-up on shore, where they incessantly chew the narcotic leaf 'qat' and dream of sharing in the huge ransoms that can run into millions of dollars.

(Source: The Age)

The above article is but one of many in the press in recent times reflecting how present day pirates operate. Pirates are still ruling the high seas, but historically what triggered their choice of lifestyle and why are they still active in the $21^{\text {st }}$ century? Could actions in the past have eradicated the pirate industry a long time ago or is it just part of natural evolution?

\section{Introduction}

Let us begin by going back in time and unravelling the rationale behind the formation of pirates on the high seas. The structure aboard a pirate ship was built around democracy and the separation of powers; whereas, merchant vessels were run in an autocratic manner, with a captain appointed by the owner in charge, controlling the ship and crew with all encompassing power. The evolution of piracy as an alternative occupation was mainly triggered by abusive work conditions and maltreatment aboard merchant vessels, which gave rise to mutiny (Leeson 2007). Parallels can be drawn to the Shapiro-Stiglitz model of involuntary unemployment, which discusses how the perceived utility from working has to exceed the one of 
unemployment. Seamen that were maltreated aboard merchant ships perceived a low utility in being on the right side of the law subsequently minimising their transition cost to piracy. Due to the non-hierarchical nature of pirate ships, the crew worked in harmony and unison seeking the most beneficial outcome, as opportunistic behaviour was favourable to all.

Historically on merchant vessels the interest of the owner and the captain were aligned to overcome the principal/agent problem and minimize moral hazard issues, by appointing the captains through familial links and giving them shares in the vessel they operated to encourage efficient operation whilst at sea (Leeson 2007). This contractual mechanism worked efficiently with regard to mitigating the principal/agent (P/A) problem in the owner and captain relationship. Though the $\mathrm{P} / \mathrm{A}$ problem between owner and captain was mitigated, the P/A problem between owner/captain and the remaining crew still existed. In order to address this, appropriate incentives need to be offered to all onboard.

It is a well established fact in economic theory that when incentives are aligned through an effective contract the moral hazard problem can be mitigated between the principal and agents. For instance, a simple two-part wage structure, such as a base wage plus a bonus enables the owner of the ship to motivate the captain to work in his interest. However, only if such a system is extended to all crew members are all incentives aboard a given ship aligned.

As pirate ships were not acquired legitimately but were stolen, the scope for contractual complications arising between the crew and the absent owner was minimised (Leeson 2007). Pirate ships appointed a captain who worked as an autocrat when pursuing a target or escaping an unsuccessful attack to mitigate conflicting debates in tense situations. In all other instances the captain was on equal terms with the crew and even slept beside them. Furthermore, the captain was democratically elected and could also be removed democratically, which kept the intentions of the captain focused on joint utility maximisation. 
HYPOTHESIS

Implied contracts upon pirate ships mitigated the P/A problem more effectively than merchant ships.
MARKET FAILURE

The P/A problem on merchant vessels created a negative externality on the shipping industry by indirectly encouraging piracy.
MARKET SOLUTION

Apply the conceptual agreement of pirate ships to merchant vessels.

In seeking to replace the hierarchical structure on a merchant vessel with the one found on pirate vessels, the major issue faced is moral hazard, predicated on the $\mathrm{P} /$ A problem. When the vessel is at sea, the absent owner is unable to measure the efforts of the captain and crew (agents), individually or collectively, to ensure his interests are being satisfied. This illustrates the classic predicament that results in the $\mathrm{P} / \mathrm{A}$ problem in any contractual relationship where rationally opportunistic agents act autonomously, which results in non-pareto optimal behaviour apropos the interest of the principal. This situation occurs because the owner is separated from the agents and cannot costlessly monitor or measure their performance; for instance, by virtue of the crew out at sea their self-interested behaviour, which is at odds with the interests of the owner, is exacerbated. The challenge faced when applying the democratic structure of a pirate ship to merchant vessels, is being cognizant of the owner's interest.

We now look to a model based on Salanie (2005) to stress more methodically, the contractual feature between the pirate and merchant ships. To simplify, assume that delivering the required outcome is an unknown factor, $\mathrm{S}$ denoted for success and $\mathrm{F}$ for failure, dependant on the agent contributing either a high level of effort $\left(e_{H}\right)$ or a low level of effort $\left(e_{L}\right)$ The utility function of the agent is denoted $f(\mu)=$ 
$\mu(w)$ - e which implies that the utility $(\mu)$ is a positive function of the wage paid $(w)$ and a negative function of the effort expended (e). The probability of success if the agent contributes action $e_{H}$ is $P$ and $e_{L}$ is $p$ (or $1-P$ ). This can be simplified to give us the agent's incentive constraint:

$$
P \mu\left(w_{S}\right)+(1-P) \mu\left(w_{F}\right)-1 \geq p \mu\left(w_{S}\right)+(1-p) \mu\left(w_{F}\right)
$$

this can be further simplified to

$$
(P-p)\left(\mu\left(w_{S}\right)-\mu\left(w_{F}\right)\right) \geq 1
$$

Effectively, the incentive constraint suggests that the agent will weigh the probability of success with the utility gained and the added wage received in deciding what level of effort to contribute. When equation (1.2) holds, the agent will contribute a high effort and the principal will have to pay the higher wage when the agent works. Note that the difference between $\left(\mathrm{w}_{\mathrm{s}}-\mathrm{w}_{\mathrm{F}}\right)$ will have to increase as $P$ diminishes towards $p$ to ensure the agent's motivation to contribute the high level of effort is maintained.

The payoff of the principal (the owner), denoted by $x$ can be written as

$$
f(x)=P\left(x_{S}-w_{S}\right)+(1-P)\left(x_{F}-w_{F}\right)
$$

So the principal aims to maximise payoff. The P/A problem is neatly visualised in the notion that when the likelihood of success $(P)$ increases, the principal will prefer a constant wage of $\mathrm{w}_{\mathrm{S}}=\mathrm{w}_{\mathrm{F}}=\mathrm{w}$ when the agent would like $\mathrm{w}_{\mathrm{S}}$ to be even higher. This leads to the problem of "hold-up" where the revelation of additional information about the probability of success or failure in a venture leads to changes in relative bargaining power between the principal and agent. Wage or contract renegotiation or even strikes or mutiny are evidence of this sort of effect. 
This simple framework of a two-part wage framework suggests how incentives can be provided to agents such that they work in the interest of the owner without having to resort to appointments based on shares and familial connections. The real challenge in this application is to formulate and implement a system that allows for incentives to encourage a high level of effort transferable through all ranks of crew aboard a vessel.

As previously discussed, merchant vessels operate under an extremely hierarchical structure, giving the mainstream crew no choice but to obey and contribute or be punished at the captain's discretion. Under this structure, much is within the captain's control which can result in disunity amongst the sailors. As previously mentioned, the owner can address the moral hazard concerns with the manager by offering a two-part wage framework. This system focuses on success or failure, though not taking into account whether the captain succeeds at the expense of his crew. Therefore, with regard to applying the more horizontal structure of pirate ships successfully to merchant vessels, it is necessary to account for the factor of crew satisfaction. Crew satisfaction is an intangible factor and therefore faces measurement difficulties, though pirates on the whole do work in unison, whilst it is proven that crew upon merchant vessels have historically been somewhat oppressed.

An alternative remuneration structure that provides an incentive to the entire crew to contribute a high effort is needed. This remuneration structure could be an incentive based bonus system applicable to all crew onboard the merchant vessel. The analysis addresses how a system consisting of a base wage $\left(\mathrm{w}_{\mathrm{b}}\right)$ with an added fixed bonus would work (Dutta 1999). The bonus (B) would be a fixed rate rewarding all crew equally, irrespectively of rank, but the agents would only receive the bonus when a successful outcome is achieved and would entail a disutility (d) associated with the chosen effort, therefore yielding $e_{H}$ takes $d_{H}$ and $e_{L}$ takes $d_{L}$. The incentive constraint of the agent would then become 


$$
P \mu\left(w_{b}+B\right)+(1-P) \mu\left(w_{b}\right)-d_{H} \geq p \mu\left(w_{b}+B\right)+(1-p) \mu\left(w_{b}\right)-d_{L}
$$

which can be derived to give us the following condition

$$
(P-p)\left(\mu\left(w_{b}+B\right)-\mu\left(w_{b}\right)\right) \geq d_{H}-d_{L}
$$

In other words, this simply means that the probability for receiving the bonus has to be higher or equal to the extra disutility it costs the agents to perform the high effort. This also means that when the probability for success $(P)$ gets closer to the probability for failure $(p)$ when performing the high effort, $d_{H}$ goes toward $d_{L}$, which increases the disutility; and the incentive for performing the high effort moves towards zero. A potential problem of having a fixed bonus system across all agents is that of a free rider problem where agents do not necessarily contribute at the same level of intensity. This would be mitigated by peer pressure and the possibility of loss of future employment.

The pay-off of the principal (owner) would be altered to

$$
f(x)=P\left(x_{S}-w_{b}-B\right)+(1-P)\left(x_{F}-w_{b}\right)
$$

The owner as a capitalist is interested in profit maximisation. With the wage being a base wage estimated for the agent's level in the hierarchy, the additional cost for the principal simply consists of the bonus. For this system to work, the principal needs to find it beneficial for the agent to contribute a high level of effort, meaning the added pay-off needs to exceed or equal the extra cost of the bonus or

$$
P\left(x_{S}\right)+(1-P)\left(x_{F}\right) \geq P\left(w_{b}+B\right)+(1-P)\left(x_{F}+w_{b}\right)
$$

The bonus achieved is a lesser percentage of the wage for the higher ranks but this is justified by fact that the lower ranking crew need to work harder for success to 
occur than the captain. This system provides the incentive to work because the bonus is of higher value to them.

Altering the hierarchical structure upon merchant vessels would not be an easy task, although the structure upon pirate ships is by far more efficient, effectively maximizing the utility of all involved. The prize gained from piracy was divided equally among the crew after subtracting awards given for injuries and portions drawn by the captain and a few elected men (Salanié 2005). The equality of this system can be related to the equality of the division of the bonus in the two-part wage framework.

\section{Conclusion}

As witnessed recently in the press, there has been a resurgence of piracy off the coast of Africa, netting pirates large cash ransoms. In this paper we explore the application of the contractual structure onboard pirate ships to merchant vessels as an exercise in solving the dilemma of an absent owner with no prospect of monitoring or measuring the performance onboard the ship when at sea. Since agents act autonomously and are opportunistic by nature, a low effort is what a crew should be expected to provide when the principal is far removed from the agents.

By applying a two-part wage framework, such as on a traditional pirate ship, in the owner captain contractual relationship the principal/agent problem can be minimised. To ensure crew satisfaction on all levels, a wage plus bonus scheme can be applied. The base wage can be estimated on the level of rank, and the bonus can be a fixed rate rewarding all crew equally. This would increase incentive for lower ranked crew to perform at a higher level and the crew would work in unison increasing their utility as well as maximise the owner's returns. 
Since pirate ships exist today in spite of their illegality, they perhaps do so in part because the contractual relationships they operate by have an evolutionary advantage to those used by the merchant ships. If this is true, then their current success is a path dependent outcome of practices they adopted several centuries ago. If merchant vessels had adopted aspects of the contractual relationships aboard pirate ships in the past, it might well have reduced that evolutionary advantage and eradicated the pirates of current times.

\section{References}

- Dutta, P K 1999, “Strategies and games: theory and practice”, Massachusetts Institute of Technology, pp. 294-307.

- Leeson, P T 2007, "An-arrgh-chy: The Law and Economics of Pirate Organization”, Journal of Political Economy, Vol. 115, (6).

- Salanié, B 2005, “The economics of Contracts”, Massachusetts Institute of Technology, $2^{\text {nd }}$ ed, pp. 119-156.

- The Age 2008, “Somila's Pirate Kings", The Age, Retrieved 20th Nov 2008, <http://www.theage.com.au/articles/2008/11/19/1226770542082.html> 